\title{
Engaging Youth In Creating A Healthy School Environment: A Photovoice Strategy
}

Carol Henry, Ph.D., University of Saskatchewan, Canada

Dan Ramdath, Ph.D., Research Scientist, Agriculture \& Agri-Food Canada \& University of the West Indies. Trinidad \& Tobago Judy White, Ph.D., University of Regina, Canada

Sharon Mangroo, Ph.D., Ministry of Education, Trinidad \& Tobago

\begin{abstract}
This study examined a pilot participatory needs assessment that was conducted with nine senior high school students from Port of Spain, Trinidad. Photovoice was used to engage these students in critical dialogue about their perceptions of issues affecting their health. Trained graduate students facilitated a 3-day training session in photovoice techniquelethics, writing narratives, critical reflection and dialogue with these students. Once trained, they were given disposable cameras and asked to photograph their school environment and document their thoughts on what they had photographed. After collation of photos and dialogue, seven health themes emerged. The most recurring themes included quality of the food served at schools, need for safe, clean and well-maintained school facilities, and role modeling by teachers, parents and community. Recommendations to address the concerns identified were discussed by the participants. The study concluded that conducting needs assessment, which concentrates on the voices of those affected, can be a first step in creating successful and cost-efficient programs and interventions tailored to specific groups. A needs assessment using photovoice should be a technique considered by school staff, government leaders, health professionals, and NGOs.
\end{abstract}

Keywords: Photovoice; School Health Promotion; Participatory Action Research

\section{INTRODUCTION}

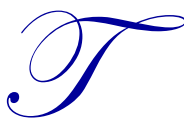

he enhancement of children's physical, mental, and social well-being and the promotion of healthy school children require new partnerships and collaboration among a broad range of community partners and children themselves. To form these new partnerships certain barriers must be overcome such as those related to strengthening the involvement of the community as a source of power in decision-making. Research has shown that active involvement of children in decisions affecting them has important benefits to their growth and development (Strach \& Magill, 2004). The growing interest in children's perspectives has been stimulated by a variety of influences, for example, the United Nations Convention on the Rights of the Child (UNICEF, 1998), and political initiatives in many countries aimed at safeguarding children's interests. There are also economic reasons for this growing interest, illustrated primarily by the strong influential views of children (and their parents) as "consumers" or "users" of educational provisions (Bae, 2009).

It is well accepted that if children have optimal health and learning this could ultimately lead to a stronger future for the country in which they reside. Given that children are the most vulnerable and dependent members of society, their health can be regarded as an index of overall health in the society in which they live (California Project LEAN, 2007). Childhood obesity has reached epidemic proportions in Canada (Tremblay, Katzmarzyk \& Willms, 2002; Ballew, Kuester \& Gillespie, 2000), and has now become a global problem (Raine, 2012; Popkin, 2011). Achieving healthy weights for children should be of paramount importance as most of the diseases in adulthood have their origins in childhood- cardiovascular diseases, type 2 diabetes and mental issues (Barker, 2012).

Within early childhood educational traditions, listening and responding to children's needs have been recognized as central to good practice (Bae, 2004). In settings-based health promotion (Tones \& Green, 2004), key 
values and pillars underpinning the health- promoting school's approach offer strong support for children's involvement, empowerment, and action competence. Further, active participation of children in learning about health and health improvement has been emphasized as one of the important tasks of health promoting school (Clift \& Jensen, 2005; Tones \& Green, 2004). The health promoting framework is made up of five pillars including the whole school approach to health. The whole school approach to health includes a participatory action-oriented approach to health education, valuing students own concept of health, developing the physical and social environment of the schools, and making effective links between home and the community (Stewart-Brown, 2006). The health promoting school (HPS) promotes good health and overall well-being by always strengthening its capacity as a healthy setting for living, work and play (Stewart-Brown, 2006).

Photovoice has emerged as a participatory strategy in the field of health promotion, and one way to view the social environment of children and youth (Briski \& Kaufman, 2004). Photovoice illustrates how engaging and connected to social issues research can be when it is the participants themselves who are producing the images (St. Leger, Young, Blanchard \& Perry, 2010; Wang, 2003). It is an approach that incorporates photography with participatory action methods, where participants represent their worlds with their own photographs, which can then be analyzed to surface their meanings (Tones \& Green, 2004). In practice, photovoice provides participants with cameras, so that they can represent and record their worlds and everyday realities. It uses these pictures to promote critical group discussions as well as individual interpretations of the photos produced by the participants (St. Leger et al, 2010). By documenting their own worlds, the methods places the production in the hands of students allowing for a more credible and authentic work of art that cannot always be achieved; the images they produce, young people can initiate grassroots change (Strach \& Magill, 2004). It is this lack of artifice in the not-always-technicallyperfect images that sometimes makes them more convincing and more true to life. There is an increasing body of literature from a variety of areas and contexts that support the effectiveness of this methodology (Strach \& Magill, 2004; Wang, 2003; Wang \& Pies, 2004) as a tool for social critique (St Leger et al, 2010).

This study sought to collate insights from a university-community partnership that explored the use of photovoice to elicit the voices of children. Through the use of cameras students were given an opportunity to create "images of their worlds" and share their recommendations and insights with policymakers. The sharing was carried out through a multi-stakeholder public forum - jointly held by the partners. The overall goal of this study was to use photovoice to promote a participatory approach which provided a unique opportunity for children to collaborate in decisions that affect their health and wellbeing.

\section{METHODOLOGY}

\section{Stage 1: Community Buy-in}

The first stage of this study could be described as a 'community-buy-in' phase in which members of the research team partnered with community stakeholders to jointly determine the goals and objectives of the photovoice project. Policy makers, advocates, and administrators are often recruited to act as an advisory board for individual projects (Wang, 1999), when creating an action-oriented approach. The advisory board allowed participants to have a direct line of communication with the people authorized to plan for their school community. In our study, we recruited nine senior high school students from local high schools in Port of Spain, Trinidad and Tobago. The students were selected using a purposive sampling technique, with the understanding that the results from the study would be provided for the design of, and intervention/policies to address health promotion in schools. The study was approved by the research ethics board of the Faculty of Medical Sciences, University of the West Indies and the behavioural ethics board of the University of Saskatchewan. Parents gave informed consent and the students assented to participation in the study. The goals of the study were explained to the students as being: (1) to explore personal health priorities and factors that influence their daily lives through participatory research; (2) to reflect, think critically and dialogue about their exploration; and (3) to make recommendations to be presented to pertinent stakeholders. Researchers, school administrators and community partners (curriculum officers) formed the advisory team in mentoring students throughout the life of the project. 


\section{Stage 2: Training and Picture Taking}

After recruitment, a 3-day training and information workshop was conducted with participants. The training included an orientation to the subject area and building relationships with the participants. Although researchers can establish themes in advance for pictures to be taken, we felt that it would be much more beneficial if the themes were determined through dialogic interactions with participants. It was expected that the end result would be a more open and community-driven data collection. For our study students participated in initial discussion for the focus of the project during the 3-day training and information workshop conducted. Discussions during the workshop highlighted gaps in children's knowledge and attitude pertaining to adopting a healthy lifestyle, as well as factors influencing the delivery of health promotion in schools.

A necessary technical consideration is the type of camera to provide to the participants. The workshop began with the facilitators providing an orientation to the subject area - photovoice and the related ethical issues associated with using their camera to take and create images. The potential risks of taking community-wide photographs were discussed. Participants then moved to discussions about personal health, participated in exercises in communication and critical reflection strategies, and practiced using the camera. During the workshop, participants participated in a free-write session where they shared their perceptions about health. A brain storming session was also held to discuss themes that might be important to addressing health and healthy environment at home, school and community.

Each study must make a determination based on cost, length of project, and participant familiarity. If the study involves a population unfamiliar with photography it may be beneficial to include initial training sessions on camera use. After careful consideration, the team chose to distribute a single disposable camera to each participant. This allowed for a straightforward 'point and shoot' usage of the camera (for participants) which minimized training. The costs were also more reasonable than providing digital cameras or relying on students' own cameras (e.g., on cell phones) for data retrieval.

The training for the three-day workshop was facilitated by trained graduate (MSc) student researchers from the University of Saskatchewan. Graduate students, themselves, received training in qualitative research, governance and critical reflection prior to this field-based research on conducting photovoice workshops. Graduate students were also mentored through the photovoice workshop process by faculty members of the research team from the University of Saskatchewan and the University of the West Indies, St Augustine.

The photovoice method requires that the aims of the study and the ethical issues surrounding taking pictures in the community be reviewed with participants prior to them giving their consent to participate. It was important that these issues were understood in order that privacy was protected. Participants were reminded to think and act critically as they explored their environment during the process. At the end of the workshop, all invited participants agreed to take part in the study. Pictures were to be taken over a 4-day period, starting on a Friday and ending on a Monday. Participants were encouraged to take pictures of indoors and outdoors around their school community. Students were given contact information for the workshop facilitators and faculty project team if questions arose during the research period. At the end of the 4-day period, a one day workshop was held. During the workshop students presented their pictures for discussion and reflection.

\section{Stage 3: Photo Selection, Focus Groups and Analysis}

Participants were brought together in focus groups. These groups discussed the selection of the photos taken. The advantage of the focus groups was that each person would bring their own perspective to contextualizing the data. To facilitate the discussion, the researchers developed a double set of prints from each role of film. One set of photos was given to each participant prior to the focus group discussion to allow them to self-reflect on the images. During the focus group session, the second set of photos were distributed; students were asked to select the top 10 for discussion; following discussion they then were asked to select the top five for each student. The SHOWeD* method was used to analyze and free-write about the top 5 photos (Strach \& Magill, 2004; Wang \& Plies, 2004; Kroeger, 2004). The format decided in reflecting was to respond to the following guiding questions, What do you See here? What's really happening here? How does the picture relate to our lives? Why does this 
problem or strength exist? What are the root causes? How might we become empowered now that we better understand the problem? What can we do about it? (Wang, 1999). Photovoice participants reflected critically on what the images meant to them when thinking about their own health and well-being. They discussed how the images represented their experiences and how those experiences were related to their own health (Wang \& Burris, 1994). Although general questions were asked, most of the discussion was free flowing. The discussion was audiotaped so that exact quote could be used in reports, articles, and in the pictorial scrapbooks provided to each participant at the end of the study.

Following the focus group sessions the two graduate student facilitators conducted further analysis in conjunction with the findings from the literature. They also created scrapbooks of photos and quotes from selected participants. Similar to findings among other Photovoice researchers, the photographic method seemed to foster a sense of pride and confidence among the participants (Strach \& Magill, 2004) and to the graduate student facilitators. The findings were presented during a the National Symposium which was hosted by the partners, Trinidad and Tobago's Ministry of Education, the University of the West Indies, St Augustine campus, and the University of Saskatchewan, to look at policies in place to support a health promoting school framework.

\section{Trustworthiness of the Data}

Trustworthiness in qualitative research helps to produce findings that can be trusted and is worth paying attention to (Lincoln \& Guba, 2005). In this research, Guba's model of trustworthiness was adhered to, particularly, principles of credibility, transferability, dependability, and conformability were maintained.

\section{RESULTS}

\section{Stage 4: Results and Community Change}

Children and youth's eating patterns are influenced by several factors such as individual food preferences, family meal patterns and parental role modeling. Nonetheless, it has become clear that children and youth's eating habits are also determined by social norms and the environment in which they learn and play. Since children spend a significant amount of time in school, this environment can have an influence on their eating patterns. School age children spend at least 6 hours at school every weekday where they consume on average 35\% of their daily food intake, and expend up to $50 \%$ of their daily energy.

Five themes characterized the views of these youths regarding the factors within their environment that influence their health and wellbeing.

\section{Theme 1: Food at School}

Through the focus group discussion, students shared their perception of the food served in schools as part of the national school feeding program and a la carte (competitive foods). Several participants commented on the benefits of school meal. They said that schools meals are provided by the government, free of charge to students nationwide, that two meals (breakfast and lunch) are provided on a daily basis and it assists the students who cannot afford these meals and those who don't have time to prepare these meals. One participant noted, "The meals are very healthy and are prepared under very sanitary conditions". However, there were also pictures of food served at school that students perceived as unhealthy. Said one participant: "This is the cheapest and most favorable combo that you could get at the school's cafeteria. This is not what I would call a healthy subsistence or a healthy way of living, especially for developing a student's mind. The Pepsi is not even 'diet', and the pie is not oil free." Another participant expressed concern for the types of beverages, noting the location of the beverages as well as the associated costs: "This is a photo of a refrigerator in a school café. If you look closely, you'll see that to the top left hand corner there is a small section of water. Look at the ratio of water to soft drink. In our school, soft drink is also cheaper than water; therefore it is bought more frequently as compared to water."

Food and beverages at school are classified into three main categories: (1) the Government's national school feeding program, (2) foods and beverages consumed outside the formal meal program, especially à la carte 
items available in school serveries, and venues outside the server, known as street food, and (3) food brought from home. The latter are known as competitive foods due to the fact that they compete with the school meal program. Trinidad and Tobago's National School Feeding Program is a governmental policy aimed at supplying lunch meals that provide 33\% of the nutritional requirements of the students enrolled in public schools during their day at school. Furthermore, this program targets reducing the school dropout rates, building healthy eating habits and increasing the learning ability (Ministry of Education, Trinidad and Tobago, n.d.).

Theme 2: Places to Eat: Environmental Spaces were of concern to students.

Several students commented on the school environment as it relates to quality eating-places. "This represents how I feel about the absence of proper eating facilities in my school. These young men have no other alternative, but to dine by the male toilets." One comment related to nearby vendors outside the school premises. There is a man who owns this yellow stall. He also makes these drinks right on his stall and throws his garbage away in the bin. Some people tend to keep bins right next to foodstuff or anything that is edible. It is unhealthy. This a concern because there is a lot of harmful bacteria in dust bins and if you have food right next to it, the bacteria can get on your food \& make you sick." Successfully managing a school environment is an essential educational investment. Research has shown that there is a clear link between environmental quality of schools and educational performance: facility management systems determine environmental quality in schools, the quality of the school environment shapes attitudes of students, teachers and staff (Clark, McQuail \& Moss, 2003).

\section{Theme 3: Physical Education at School}

It is a known fact that physical activity improves overall health (Fairclough \& Stratton, 2005). Not only does it improve circulation, increase blood flow to the brain, and raise endorphin levels, which all help to reduce stress, improve mood and attitude, and calm children, physically active students may also achieve more academically. Physically fit students are less likely to miss school, partake in risky behaviours, get pregnant, or attempt suicide, which are all associated with better outcomes in school (Taras, 2005; Kantomaa, Tammelin, Demakakos, Ebeling, \& Taanila, 2010; Goodhart et al. 2006). Many studies have demonstrated the positive effects of physical education and physical activity on school performance. Several studies have stated that providing increased time for physical activity can lead to better concentration, reduced disruptive behaviours and higher test scores in reading, math and writing (Goodhart et al, 2006; Satcher, 2005).

In general most participants expressed support for the role that physical activity play in their daily lives. There were also a few comments on the need to ensure appropriate facilities for children to play. One participant said: "Here I see a football field, surrounded by lots of trees and a beautiful midday sky. A normal school day, two students can be seen sitting by the trees, talking in the cool breeze. There are plans to build a sewer on this lovely field. I think football is the richest resource that the school has to offer, to keep students out of trouble. We should protest and take action".

\section{Theme 4: Social, Mental and Spiritual Health}

The study participants identified several school elements that would promote mental health. The following quotes illustrate their views:

Friends are necessary because they are the ones we go to when we are stressed, need someone to talk to or just have a sudden urge to laugh at or with each other. When we are around those who truly are our friends, we feel comfortable with being ourselves. True friends accept us for who we are inside.

Class is in progress, teachers are not inquiring where their students are. When students stay away from class, teachers are not motivated to teach. They refuse to teach a small amount of students. I, being part of that small amount, am at a loss. Having friends increases social health, while having sexual relations increases risk for physical diseases. It is important that if you are having a sexual relationship with someone, to get tested for the various STD's before the relationship begins. 
The affective/social aspects are important to student health. In order for children to meet developmental milestones, learn, grow and lead productive lives, it is critical that they be healthy. Good social-emotional and mental health is a key component of children's health and healthy development.

\section{Theme 5: Families as Role Models}

Parents and caregivers influence children's eating through the type of foods they provide, how meals are structured, their parenting style, role modeling and the family and social environment. Positive early childhood experiences regarding food and the social environment in which children eat are critical to the development of healthy eating habits later in life. Students recognize the importance of good family models as contributors to good health. They said, "adults ... should set good examples for children to follow" meaning that adults should be role models.

\section{CONCLUSIONS: LESSONS LEARNED}

Photovoice was valuable as it empowered students to become more aware of their surroundings. Students saw themselves as researchers collecting data, analyzing that data, and doing something with the data to help solve problems. It provided a process and resources for students to amplify their voices in order to influence and gain power to shape school policies (Goodhart et al., 2006). Photovoice facilitated greater involvement of the participants compared to many conventional research methods. Not only did participants provide data, but through their selection of photographs and the group discussions of themes and issues, participants were also involved in data analysis. This increased participation added to the validity of photovoice studies by reflecting results that were determined and emphasized by the community studied, not by the researchers. It also proved useful as a method for engaging children and youth in discussions relating to their physical, social and other environmental factors that were thought to affect health and it actively engages students.

Photovoice offered an innovative way to triangulate research results as multiple streams of information gathering were used: visual verbal information, group discussion, and individual reflection in taking photos. When the method is used in a larger study it can help to increase reliability by comparing photovoice results to other responses such as survey responses. In our study multiple approaches used allowed for greater triangulation as well as with the literature. The camera itself provided an opportunity for participants to take the research aims and goals to a wider school community. By allowing participants to record images of their own life they interact with the public, including their schools and this creates the potential for interaction with non-participant community members and a discussion of the activity, itself which can promote the research to a wider audience.

Photovoice also plays a role in enhancing interview data as it can be used as a memory trigger to aid participants in recalling past experiences. It also allows participants to experience their world as they see it through pictures. It allows the audience to hear in words what the visual meant to them. Evidence suggests increasing success with photovoice as a method to engage groups that may not necessarily have been included in traditional research in the past. Groups like children and youth can be included in research with the ability to increase the scope of traditional research.

Engaging adolescents in health-promotion research and planning through the use of photovoice encourages them to actively think about their health in the context of their daily life, they can also influence others. Although this photovoice pilot study among high school students is limited in respect to its generalizations because of the sample size, selection methods, and uniqueness of the population, this study still suggests that this method can be successfully employed to actively involve students in shaping decisions that influence their lives. Furthermore, it may be useful for including school health programs in planning and research. This is especially important for children as they have traditionally have been left out of these decisions that affect their own health and well-being. Based on the experiences of this pilot study, it is apparent that photovoice enabled a sense of ownership among young people in the research process while also providing researchers with rich insights into the health perspectives of young people. 


\section{Limitations}

The first main issue when thinking about incorporating photovoice into a study is that participatory action research approach has the potential to require large amounts of funding due to high costs contributed by time and materials. Researchers, research staff and participants must commit to a substantial time commitment for training, data collection and follow-up discussions. To aid in recruiting, researchers may have to consider financial incentives for participants due to the time commitment required. The costs of camera equipment, processing fees, and adequately trained study personnel are important considerations also. These costs may create a barrier and inhibit researchers from conducting smaller projects.

A second issue one must taking into consideration when thinking of using photovoice as a research method is the ethical issues surrounding privacy and fair representation. A researcher cannot control what participants do while they are out in the community. To minimize potential harm, it is crucial that all participants are adequately trained in the ethics involve in proper use of cameras and data collection.

A final issue surrounds the use of the photos. Photos collected during participatory action research cannot stand alone as data. To be an effective research tool, photovoice requires the pictures to be used to facilitate participant discussion. Analysis is used to establish the meaning and relevance of each picture used as data.

\section{Recommendations}

When conducting health promotion research, the use of traditional survey methods may be enhanced by the use of photovoice as it allows participants to actively participate and reflect on what influences their health as well as to record and reflect on their health beliefs and priorities. The use of photovoice recognizes that children and youth may have insights into their own health beliefs and priorities that cannot be known or fully understood by public health professionals without employing empowering and creative techniques to obtain their true perspective. An important goal of using photovoice in health promotion is to have those who may participate in health promotion programs guide the development of these efforts to ensure their saliency and sustainability. However, in the end, the ultimate goal should be to empower children and youth to express their needs and become actively involved in the decisions that influence their lives.

\section{Implications for Applications}

This exploratory study helps to fill a gap in the literature on planning and research strategies for health promotion among children and youth. This study adds to a very small number of public health publications that discusses using photovoice with the purpose of addressing their health issues. This study provides evidence that photovoice methodology may be an effective method for engaging vulnerable groups such as children in health promotion program planning and research. Photovoice enables representatives of vulnerable populations to express their beliefs and priorities in the context of their own lives through photographic imagery.

\section{ACKNOWLEDGEMENTS}

The authors gratefully acknowledge the financial support of the Social Science and Humanities Research Council of Canada, and the Association of Universities and College of Canada. Special thanks to Trinidad and Tobago's ministry of education.

\section{AUTHOR INFORMATION}

Dr. Henry is an Associate Professor in the College of Pharmacy and Nutrition. Dr. Henry's research expertise is in child and youth nutrition, health literacy and school health. Her research is collaborative and interdisciplinary and brings together researchers from a variety of disciplines, community organization stakeholders, graduate and undergraduate students to address concerns and develop strategies for meeting the health needs of children, their families and communities. Dr. Henry's research extends locally and internationally and has established three major international partnerships in Trinidad \& Tobago; Brazil \& Ethiopia. E-mail: CJ.Henry@usask.ca (Corresponding author) 
Dr. Dan Ramdath, formerly professor of biochemistry, Head of Pre-Clinical sciences, specialist in clinical biochemistry, malnutrition and chronic disease prevention, University of the West Indies, St Augustine campus, Trinidad and Tobago. Dan is currently a senior Scientist, Agriculture and Agri-Food Canada, 93 Stone Rd W, Guelph, Ontario N1G 5C9. E-mail: dan.ramdath@agr.gc.ca ; 519-226-8082

Dr Judy White, Associate Professor and Associate Dean, Faculty of Social Work, University of Regina, Regina, Saskatchewan, Saskatoon Campus, is a population health specialist with special expertise in mental health, international and indigenous health. Judy is an active member of the team with broad experience in both national and international settings Her works includes a focus on social issues and concerns facing Canada's north. . Contact: judy.white@uregina.ca; 306-684-7375

Ms. Sharon Mangroo, Chief Education Officer, Ministry of Education, Trinidad and Tobago, and local coinvestigator collaborated jointly on the design, implementation and evaluation of the project. Contact: Office of the CEO, 18 Alexandra St; St Clair, Port of Spain, Trinidad and Tobago; 876-628-7350.

\section{REFERENCES}

1. Bae, B. (2009). Children's right to participate: Challenges in everyday interactions. European Early Childhood Education Research Journal, 17(3), 391-406.

2. Ballew, C., Kuester, S., \& Gillespie, C. (2000). Beverage choices affect adequacy of children's nutrient intakes. Archives of Paediatrics \& Adolescent Medicine, 154(11), 1148-1152.

3. Barker, D. J. (2012). The developmental origins of chronic disease in later life. Nutritional Health, 59-83.

4. Briski, Z. \& Kaufman, R. (2004). Born into brothels: Calcutta's red light kids [Motion picture]. New York: THINKFilm.

5. California Project LEAN (Leaders Encouraging Activity and Nutrition). (2007). Captive kids: Selling obesity at schools: An action guide to stop the marketing of unhealthy foods and beverages in school. Retrieved (8/13/2012) from www.californiaprojectlean.org/Assets/1019/files/CK2007.pdf

6. Clark, A., McQuail, S. \& Moss, P. (2003). Exploring the field of listening and consulting with young children. Research Report No. 445. Thomas Guyam Research Unit, University of London. Retrieved (01/112012) from http://dera.ioe.ac.uk/8367/1/RR445.pdf

7. Clift, S. \& Jensen, B.B. (Eds.). (2005). The health promoting school: International advances in theory, evaluation and practice. Copenhagen: Danish University of Education Press.

8. Fairclough, S. \& Stratton, G. (2005). Physical education makes you fit and healthy. Physical education's contribution to young people's physical activity levels. Health Education Research, 20(1), 14-23.

9. Goodhart, F.W., Hsu, J., Baek, J.H., Coleman, A.L., Maresca, F.M., \& Miller, M.B. (2006). A view through a different lens: Photovoice as a tool for student advocacy. Journal of American College Health, 55(1), 53-56).

10. Kantomaa, M. T., Tammelin, T. H., Demakakos, P., Ebeling, H. E. \& Taanila, A. M. (2010). Physical activity, emotional and behavioral problems, maternal education and self-reported educational performance of adolescents. Health Education Research, 25(2), 368-379.

11. Kroeger, S., Burton, C., Comarata, A., Combs, C., Hamm, C., Hopkins, R. \& Kouche, B. (2004). Student voice and critical reflection: Helping students at risk. Teaching Exceptional Children 36(3), 50-57.

12. Lincoln, Y.S. \& Guba, E.G. (2005). Naturalistic Inquiry. Newbury, CA: Sage Publications.

13. Ministry of Education, Government of the Republic of Trinidad and Tobago. (n.d.). Units: National Schools Dietary Services. Retrieved (7/12/2012) from http://moe.gov.tt/units_sds.html.

14. Popkin, B. M. (2011). Does global obesity represent a global public health challenge? The American Journal of Clinical Nutrition, 93(2), 232-233.

15. Raine, K. D. (2012). Obesity epidemics: Inevitable outcome of globalization or preventable public health challenge? International Journal of Public Health, 57(1), 35-36.

16. Satcher, D. (2005). Healthy and ready to learn: Research shows that nutrition and physical activity affect student academic achievement. Educational Leadership (63), 26-30. 
17. St Leger, L., Young, I., Blanchard, C., \& Perry, M. (2010). Promoting health in schools: From evidence to action. Saint-Denis, France: International Union for Health Promotion \& Education. Retrieved $(01 / 11 / 21012$ from

http://www.iuhpe.org/uploaded/Activities/Scientific_Affairs/CDC/School\%20Health/PHiS_EtA_EN_WEB .pdf

18. Statistics Canada. (2010). Food statistics. Catalogue number 21-020-x. Retrieved (01/11/2012) from http://www.statcan.gc.ca/pub/21-020-x/21-020-x2009001-eng.pdf

19. Stewart-Brown, S. (2006). What is the evidence on school health promotion in improving health or preventing disease and, specifically, what is the effectiveness of the health promoting schools approach? Health Evidence Network Report. Copenhagen, World Health Organization Regional Office for Europe. Retrieved (01/11/2012) from http://www.euro.who.int/ data/assets/pdf file/0007/74653/E88185.pdf

20. Strach, R. \& Magill, C. (2004). Engaging youth through photovoice. Journal of Health Promotion Practice, 5(1), 49-58).

21. Taras, H. (2005). Physical activity and student performance at school. Journal of School Health, 75(6), 214-218.

22. Tones, K. \& Green, J. (2004). Health Promotion: Planning and strategies. London: Sage Publications.

23. Tremblay, M.S., Katzmarzyk, P.T., \& Willms, J.D. (2002). Temporal trends in overweight and obesity in Canada 1981-1996. International journal of obesity and related metabolic disorders. International Journal of Obesity and Related Metabolic Disorders, 26(4), 538-543.

24. UNICEF. (1998). Implementation handbook for the Convention on the rights of the child. New York/Geneva: United Nations Children's Fund.

25. Wang, C. \& Burris, M. A. (1994). Photovoice: Concept, methodology, and use for participatory needs assessment. Health Education \& Behavior, 24(3), 369- 387.

26. Wang, C. \& Pies, C. (2004). Family, maternal and child health through photovoice. Maternal and Child Health Journal, 8(2), 95-102.

27. Wang, C. (1999). Photovoice: A participatory action research strategy applied to women's health. Journal of Women's Health, 8(2), 185-192.

28. Wang, C. (2003). Using photovoice as a participatory assessment and issue selection tool: A case study with the homeless in Ann Arbor (pp. 179-196). In Minkler, M. \& Wallerstein, N. (Eds), Community-based participatory research for health. San Francisco: Josey-Bass. 


\section{NOTES}

